\title{
$9-22$
}

\section{IMAGINARIO ESPACIAL EN LA NARRATIVA CHILENA RECIENTE: EL ACUARIO COMO REPRESENTACIÓN DE LA INTIMIDAD EN RELATOS DE CONTRERAS, ZAMBRA Y BOLAÑO ${ }^{1}$}

Spatial imaginary in recent Chilean narrative: the aquarium as representation of intimacy in Contreras's, Zambra's and Bolaño's novels

Macarena Areco Morales*

Resumen

El objetivo de este trabajo es analizar el acuario como una figuración espacial del imaginario social en tres novelas escritas por autores chilenos en las últimas dos décadas, El nadador (1995) de Gonzalo Contreras, La vida privada de los árboles (2007) de Alejandro Zambra y Monsieur Pain (1999) de Roberto Bolaño. Su finalidad es atisbar en la configuración imaginaria de los espacios de la intimidad y de la intemperie en la posdictadura chilena y, más generalmente, en el entorno global en que se desarrolla la tercera fase del capitalismo multinacional.

Palabras clave: Imaginario Social, Narrativa Chilena reciente, Intimidad, Intemperie, Posdictadura.

\section{Abstract}

The aim of this article is to analyze the aquarium as a spatial figure of social imaginary in three novels written by Chilean authors in the past two decades, Gonzalo Contreras's El nadador (1995), Alejandro Zambra's La vida privada de los árboles (2007) and Roberto Bolaño's Monsieur Pain (1999). My purpose is to inquire about the imaginary configuration of spaces that refer to intimacy and the shelterless in the context of chilean postdictatorship and, more generally, in the global environment of the third stage of multinational capitalism.

Key words: Social imaginary, Recent Chilean narrative, Intimacy, Exteriors, Postdictatorship.

\footnotetext{
${ }^{1}$ Este artículo forma parte del Proyecto Fondecyt No 1100543 "Cartografía de la novela chilena reciente".
} 


\section{INTRODUCCIÓN}

El acuario, con sus connotaciones de encierro, visibilización e inmovilidad, es una imagen que se repite en las producciones culturales de los últimos años, tanto en Chile como en Latinoamérica. ${ }^{2}$ Entre las novelas chilenas recientes al menos tres le otorgan un lugar importante: El nadador (1995) de Gonzalo Contreras (1958), Monsieur Pain (1999) de Roberto Bolaño (1953) y La vida privada de los árboles (2007) de Alejandro Zambra (1975). Considerar el acuario como un fragmento del imaginario social permite vislumbrar representaciones ideológicas respecto al espacio y al sujeto en el Chile actual y en su entorno mundializado. De ahí que este ensayo analice los modos específicos en que este aparece en cada obra para mostrar cómo ha sido construida tal figura, algunos de sus rasgos principales y también su destrucción.

\section{FIGURACIONES IMAGINARIAS}

En una investigación sobre narrativa chilena actual he intentado, por medio de un trabajo empírico que parte de la lectura de un corpus representativo de relatos, establecer una suerte de código del imaginario que está formado por unidades de distinto orden, las que han ido apareciendo en las obras estudiadas. Estas son figuras, formas o propiamente imágenes, que tienen un carácter connotativo, puesto que, además de su significado inicial, dan cuenta de un contenido de segundo grado, ${ }^{3}$ el cual se conecta con lo que Roland Barthes denomina ideología ${ }^{4}$ y con lo que Cornelius Castoriadis llama imaginario social. ${ }^{5}$ Son también metafóricas, en el sentido que le dan a ello Lakoff y Johnson, es decir, forman parte de sistemas significativos imbricados e históricos. ${ }^{6}$

\footnotetext{
${ }^{2}$ Por ejemplo, en Salón de belleza de Mario Bellatin y en el filme La vida de los peces del joven director chileno Matías Bize.

${ }^{3}$ En $S / Z$ Barthes define la connotación como "un sentido secundario, cuyo significante está constituido por un signo o un sistema de significación principal que es la denotación” (4). El esquema correspondiente es, tomando la terminología de Hjelmslev, (ERC) RC.

${ }^{4}$ Barthes sigue a Althusser en su definición: "lo evidente - por - sí-mismo", de lo que también da cuenta la noción de mito como "falsas evidencias" (8).

5 Según este filósofo lo imaginario es "creación incesante y esencialmente indeterminada (histórico-social y psíquico) de figuras/formas/imágenes, a partir de las cuales solamente puede tratarse de 'alguna cosa'. Lo que llamamos 'realidad' y 'racionalidad' son obras de ello" (12). Esta concepción se separa de la de Lacan, para quien el Orden Imaginario se relaciona con la fase del espejo, en la cual "el niño pequeño sólo se forma una imagen completa de sí mismo al verse reflejado en el espejo que es el otro" (Laplanche y Pontalis, 191). De ahí que Castoriadis enfatice que "Lo imaginario del que hablo no es imagen $d e$ " y que "Lo imaginario no es a partir de la imagen en el espejo o en la mirada del otro. Más bien el 'espejo' mismo y su posibilidad, y el otro como espejo, son obras de lo imaginario, que es creación ex nihilo" (Castoriadis, 12).

${ }^{6}$ De acuerdo con George Lakoff y Mark Johnson los conceptos se estructuran mediante metáforas, siendo estas el "entender y experimentar un tipo de cosa en términos de otra" (41). Las 
Las unidades determinadas por esta vía pertenecen a cuatro territorios ya cartografiados dentro del estudio de las representaciones imaginarias: el tiempo, el espacio, el sujeto y los trayectos. ${ }^{7}$ Siguiendo este orden, algunas de ellas son: la línea y el círculo, el tiempo cero; el laberinto y el acuario; el revolucionario, el árbol y el imbunche; la huida, la centralización y la esclavización (o imbunchización), el viaje. ${ }^{8}$

A modo de ejemplo, el laberinto aparece representado en al menos tres relatos de ciencia ficción del período, con dimensiones imaginarias diferentes. Así, en El ruido del tiempo (1987), una novela que sintomáticamente se publica poco antes del fin de la dictadura de Pinochet en 1987, los rebeldes construyen un laberinto rizomático como una estrategia que les permite destruir el poder totalitario. En cambio, en 2010: Chile en llamas (1998), que sale a la luz en 1998 en los últimos años del segundo gobierno de la Concertación de Partidos por la Democracia, la imaginación es menos optimista: un laberinto binario que conduce a los personajes al centro helado de la hacienda, en el cual son atrapados y mueren a causa de una identidad nacional monolítica y congelada, representada por el cadáver del general, que no es otro que Pinochet. Siete años después en Ygdrasil (2005), el desencanto cunde y la protagonista se piensa a sí

metáforas son sistemáticas, es decir, se presentan en sistemas coherentes; históricas, en el sentido de que son maneras de pensar que se han desarrollado en el tiempo; e inconscientes, lo que significa, entre otras cosas, que dejan fuera otras dimensiones de la experiencia. Un ejemplo es la conceptualización del tiempo como algo valioso que se expresa con palabras relacionadas con el intercambio económico, como "el tiempo es oro", "perder el tiempo", "tener tiempo", "calcular el tiempo". Lo anterior se debe a que esta manera de pensar el tiempo se ha desarrollado junto con las sociedades industriales modernas, donde el trabajo se retribuye según el tiempo invertido. Néstor García Canclini plantea que las metáforas (y las narrativas) son "Formas de organización de lo imaginario" (1999:62).

7 Esta partición es ya, por cierto, imaginaria. Diversos autores han conceptualizado estos territorios. De modo muy destacado, Bachelard se ha referido al espacio y Castoriadis a los tres primeros ámbitos e indirectamente al cuarto. La reflexión acerca de la agencia es un tópico discutido ampliamente en los estudios culturales. Culler lo explica así: "es la cuestión de hasta qué punto podemos ser sujetos responsables de nuestras acciones o nuestras acciones nos son impuestas por fuerzas que no controlamos" (60). En un estudio reciente sobre imaginarios sociales en Latinoamérica, a los que llama "la imaginación pública o fábrica de la realidad" (11), Josefina Ludmer estudia el tiempo y el espacio.

${ }^{8}$ Esta distinción metodológica no busca ocultar que estos tipos se superponen, como ocurre, por ejemplo, con figuras cronotópicas, en el sentido de Bajtín, de lo cual es un buen ejemplo la rotonda loop, espacio heterotópico que Rodrigo Cánovas (1998) distingue en Mala onda de Alberto Fuguet, que conjuga lugar y tiempo y que connota la temporalidad posmoderna, recursiva y estancada; o el laberinto que implica un ordenamiento espacial, un personaje en concordancia y un trayecto específico. No obstante estas sobreimpresiones, la distinción resulta de utilidad como punto de partida del análisis, que permite una mirada comparativa dentro de un segmento del imaginario y que, finalmente, es posible conectar con figuras estudiadas en los otros territorios. Por otra parte, se trata de una serie abierta que debe ser aumentada en la medida en que vayan surgiendo en el corpus estudiado nuevas figuraciones significativas que se repitan. 
misma como un ratón de laboratorio obligado a desplazarse por un laberinto sin salida, respondiendo mecánicamente a los estímulos a que la exponen los poderosos, mientras que el árbol mítico aparece como un laberinto rizomático, donde al sujeto no le queda más alternativa que acoplarse en cuerpo y alma, como una pieza, a un proyecto tecnológico de imbunchización que lo esclaviza. ${ }^{9}$

En este trabajo me referiré a otra representación espacial, que, al igual que el laberinto, se repite en algunas de las obras estudiadas: el acuario, el cual, junto con formas afines como la piscina y el delfinario, entrega información acerca de cómo se configuran imaginariamente los espacios de la intimidad en la posdictadura chilena y, en el caso de Bolaño, en el entorno global en que se desarrolla la tercera fase del capitalismo. Para dar cuenta de esta figura desarrollaré un análisis específico — que no será ni mitocrítico ni simbólico, pues no intentaré explicar sus sentidos arquetípicos, generales o ahistóricosen tres obras publicadas en los últimos veinte años: El nadador (1995), de Gonzalo Contreras; La vida privada de los árboles (2007), de Alejandro Zambra y Monsieur Pain (1999), de Roberto Bolaño; las dos primeras son posibles de adscribir al subtipo de la novela de la intimidad y la última a la de la intemperie, dos denominaciones con las que se puede abarcar un número significativo de novelas del período que surgen de la mencionada investigación en marcha. ${ }^{10}$

El período investigado corresponde a la posdictadura chilena, que se inserta en la tercera etapa del capitalismo, también llamado capitalismo avanzado o tardío. Sigo aquí a Fredric Jameson — quien toma esta denominación de Ernest Mandel, en lugar de sociedad posindustrial de Daniel Bell u otras como sociedad de consumo, de los medios o de la informacióndado que mientras estas últimas expresiones enfatizan la importancia de la tecnología y consideran al capitalismo y con él a la lucha de clases, superados, aquella plantea que es esta una fase más del dominio del capital, incluso la más pura, pues realiza la ampliación de este hasta límites nunca antes alcanzados, eliminando todas las modalidades precapitalistas y colonizando, no solo la naturaleza, sino también el inconsciente. En esta realidad nuestros "cuerpos posmodernos", dice Jameson, se encuentran inmersos en "volúmenes asfixiantes y saturados", sin coordenadas espaciales que les permitan tener conciencia de su

\footnotetext{
${ }^{9}$ Tomo estas distinciones de "La línea y el laberinto" de Umberto Eco, quien diferencia la figura clásica, que es lineal, con un itinerario único; de la manierista, con forma de árbol binario, donde hay muchos recorridos posibles, pero solo una salida; y de la hermética o rizomática, definida por la multiplicidad de conexiones y por su carácter cambiante.

${ }^{10}$ En esta han aparecido como imaginarios espaciales opuestos el de la intimidad y el de la intemperie. Ellos podrían dar sustento a las dos modalidades novelísticas que menciono en este artículo, pero está todavía pendiente desarrollar un planteamiento más acabado al respecto.
} 
posición, lo que los vuelve impotentes (108). ${ }^{11}$ En este trabajo iré demostrando que uno de esos espacios, como aparece en la narrativa chilena reciente, es el acuario.

\section{EL NADADOR: EL RETRATO DEL ACUARIO}

Publicada en 1995 y premiada el año siguiente por el Consejo Nacional del Libro y la Lectura, El nadador, la segunda novela de Gonzalo Contreras, relata la desaparición de Alejandra, la esposa del protagonista Max Borda, en el Santiago de los noventa y la espera pasiva a la que este se entrega en un moderno edificio de espejos: "Torre Gel”, al decir de Rodrigo Cánovas, o más precisamente acuario, según intentaré mostrar a continuación.

A pesar de que esta figura no aparece explícitamente en varios momentos se la bordea mediante formas emparentadas: el nuevo delfinario que Max observa desde su departamento, una pequeña fuente que encuentra en un paseo en la cordillera y la piscina a la que va a nadar. El delfinario es una introducción del tópico, que lo pone en escena ya desde la tercera página, destacando uno de sus rasgos fundamentales, la observación:

"Los binoculares atravesaron la oscuridad y se concentraron en un pequeño anfiteatro excesivamente iluminado:... la encandilada agua en movimiento, unos delfines ingrávidos rozando una pelota situada a una altura imposible, una orca que besaba en la boca a su atlético instructor" (15).

A la importancia de la mirada y la observación desde el exterior como una posibilidad esencial de este imaginario, la descripción de la fuente agrega otras características fundamentales: la quietud, el espacio limitado y el minimalismo, además de la fascinación que provoca en el narrador ese espacio:

De pronto, bajo las hojas flotantes y de aspecto antediluviano que cubrían casi toda la superficie de esa agua inmóvil, distinguió un pequeño pez de un vivo color naranja fosforescente, y uno de esos ojos redondos y estrábicos lo miró fijo por un segundo. Otros especímenes se escurrían entre los nenúfares. A Max siempre le asombraban esas pequeñas cosmogonías compuestas de un par de elementos; un agua casi estancada, nenúfares y unos cuantos peces anaranjados constituían un todo más perfecto que el desazonante mundo que veía a su alrededor (47-48).

Deteniéndonos en el tema de la mirada, es importante notar que así como Max "distingue" al pez, éste a su vez lo "mira fijo". De ello se deduce que la

\footnotetext{
${ }^{11}$ Sobre esto ver el libro de Jameson acerca del posmodernismo, especialmente la introducción; el segmento llamado "La apoteosis del capitalismo"; y la primera parte del capítulo final "La abolición de la distancia crítica".
} 
observación en el acuario es intercambiable: el espectador es también percibido desde dentro, mientras que el observado, junto con ser mirado, ve. Me interesa destacar lo primero, ya que da cuenta de la instancia de la narración, pues quien narra es quien observa, a lo que se agrega la eventualidad de que el narrador se vea a sí mismo como un personaje. Si bien esta posibilidad crítica solo es esbozada en El nadador, en La vida privada de los árboles, se desarrolla plenamente, lo que es una diferencia significativa entre ambas novelas.

Por último, la alusión a la piscina que aparece en la primera línea del relato permite hacer el nexo entre los delfines, los peces y la historia que se nos relata: el nadador Max Borda en su piso con paredes de espejos, "en esa especie de marasmo en que flotaba sin progresión hacia ningún destino determinado" (23, la cursiva es mía), es como el habitante de un acuario que se desplaza por el agua estancada carente de dirección. Más adelante se comprueba esta analogía en una extensa descripción de la piscina de la que hago una síntesis: "la piscina recubierta por su gran cúpula de goma blanca... una adolescente misteriosa que se deslizaba como un pez... la brillante luz que inundaba el recinto abovedado... la curiosa neutralización de los protagonistas emparejados por la tibieza del agua" (198). El espacio así definido es "un lugar perfecto para huir del mundo" privilegiado para la autorreflexión: "Bajo el agua... había entrevisto aspectos de su vida que en la superficie nunca logró apreciar" (198).

En concordancia con la figuración del acuario, el departamento de Max Borda es descrito en los términos ya precisados como lugar cerrado, que otorga posibilidades muy restringidas de movimiento, en el cual observar el exterior y mirarse a sí mismo es la única alternativa: "los amplios ventanales enfrentados a una noche infinita que insistía en agolparse ansiosamente contra los vidrios para reflejarlos a ambos sentados a la mesa" (13). Dadas estas condiciones, el énfasis de la representación — como ocurre con el maestro del autor, Henry James, cuyo Retrato de una dama se encuentra en el velador de Alejandra- está puesto en el sujeto, ensimismado en su propia interioridad, ${ }^{12}$ quien es a su vez observado por el narrador, como Borda lo hace con los delfines y los peces en el estanque (y también, al final de la novela, con Alejandra, escondida en un departamento del centro de Santiago, a quien espía usando binoculares). Podemos definir a esta clase de personaje como el sujeto del realismo psicológico, concentrado en su intimidad y entendida en este caso de modo restringido como relaciones de pareja, pues lo único que realmente le ocurre a

\footnotetext{
12 Contreras piensa que esto es esencial: "En toda buena obra literaria debiera existir una predominancia de la interioridad de los personajes; de hecho, soy un convencido de que la calidad de la obra está dada por la capacidad del escritor de llegar a lo más íntimo de los personajes, y reflejar, desde allí, la multiplicidad de sus conflictos. Digamos que debiera establecerse un rango de calidad entre el grado de compromiso con la exterioridad y, en el otro sentido, con la interioridad de sus personajes" (Guerrero, 102).
} 
Max, quien ha abandonado su trabajo en la universidad y sus mujeres, son enamoramientos y desenamoramientos. Lo mismo es válido para ellas, pues ni Alejandra ni Virginia ni Bibi desarrollan actividades laborales. De la centralidad de las relaciones sentimentales da cuenta la trama que hace y deshace los diversos triángulos amorosos que proliferan $\mathrm{y}$ que producen por su desenvolvimiento la historia: Alejandra-Max-Virgina; Virginia-Max-Bibi; MaxBibi-Salman; Max-Alejandra-Boris.

La obsesión con el sujeto y su intimidad es planteada expresamente en la alusión a "El retrato en el espejo convexo" (otro "retrato", que se suma al de James) de Parmigianino, cuadro en que el pintor observa su imagen deformada que ocupa la totalidad del lienzo, y se vuelve explícita en el comentario del sacerdote hermano de Max: "Me parece una pintura material que encierra el sicologismo de todo el arte moderno..., su universo me asfixia.... Es curioso que no haya naturaleza en él y que toda ventana al mundo esté dada por un reflejo" (39-40). Esta reflexión puede ser leída como metaliteraria, no solo por su alusión a la centralidad de la perspectiva psicológica en El nadador, sino también por la referencia al reflejo, el cual, como sabemos, es la premisa del realismo que se autodefine como mímesis de la realidad.

Yendo un poco más lejos, nadar puede interpretarse también metaliterariamente, considerando la siguiente descripción: "Cuando Max Borda se encontraba en la piscina no se preocupaba más que del estilo de su "crawl", armonioso, algo anticuado, pero eficaz" (28). Podemos interpretar lo anterior como un comentario sobre el "estilo" del autor - coordinado, seguro, funcional—, si consideramos las analogías nadar-narrar y nadador-narrador, como una indicación de la posición que Contreras ocupa en el campo narrativo chileno: practicante de un realismo psicológico que, en el cambio de milenio, sigue la estela de autores canónicos de fines del siglo XIX e inicios del XX, especialmente Henry James. Es decir, un narrador-nadador que se desplaza en un espacio textual conocido, cerrado, protegido, sin salirse de sus márgenes.

No obstante, contra los preceptos del realismo psicológico, el narrador, fascinado como Max por la vida perfecta del acuario, le otorga a su historia un final de cuento de hadas, en el cual la bonanza es tal - "la felicidad conseguida era tanta, la situación tanto más generosa con ellos de lo que nunca hubieran soñado"(294) - que no vale la pena salir de la torre de espejos y mudarse a una nueva casa más cerca de la tierra. Algo muy distinto es lo que se representa en La vida privada de los árboles, donde la experiencia de personajes enclaustrados en una intimidad totalizante es narrada, desde una mirada crítica, como insostenible. 


\section{LA VIDA PRIVADA DE LOS ÁRBOLES: LA IMPOSIBILIDAD DEL ACUARIO}

Una figuración similar de los espacios de la intimidad como acuarios y de los personajes que los habitan como peces se encuentra en la segunda nouvelle de Alejandro Zambra, La vida privada de los árboles, publicada en 2007, solo que en este caso la imagen se amplifica y la perspectiva se vuelve negativa. En este relato, que parece concentrar la trama de El nadador, su protagonista, Julián, se enfrenta a la desaparición de su mujer, Verónica, pero limitada a unas pocas horas de la noche, tiempo que aprovecha para rememorar, encerrado en su departamento, su pasada vida amorosa, además de contarle a su hijastra, Daniela, algunas historias sobre árboles.

Hay en esta obra varias referencias a un acuario que se encuentra en la sala de estar de la vivienda. En la primera de ellas se dice que Julián:

"Se acerca a Cosmo y Wanda, que continúan su invariable viaje por el agua sucia, y los observa con desmedida atención, pegado al vidrio. Súbita, teatralmente, Julián adopta la actitud de un vigilante, de un vigilante de peces, de un hombre especialmente entrenado en evitar que los peces abandonen el acuario" (51). ${ }^{13}$

Esta representación incluye los rasgos ya conocidos: los peces nadan en un espacio contaminado; su nadar no incluye la posibilidad del cambio; el personaje es un observador que pone "desmedida atención" y dispone de suma cercanía. Pero aparece algo nuevo, el hecho de que Julián no se limita a observar también es un vigilante, cuyo objetivo es evitar que sus habitantes dejen el acuario.

Si analogamos la posición de Julián respecto de los peces con la del narrador a sus personajes, podemos hacer una inferencia productiva sobre la narración del acuario: esta cumple una funcionalidad de custodia para mantener el espacio interior; es decir, una modalidad narrativa a la que podríamos llamar inicialmente novela de la intimidad que funciona como un dispositivo de vigilancia que mantiene a los personajes en el espacio cerrado y contaminado de la auto-observación. Pero esto no es lo que ocurre en La vida privada de los árboles, pues, se ha señalado, el enclaustramiento concluye en el espacio abierto de la calle, del agua de la lluvia que corre y limpia la ciudad y en la dispersión de la familia. Sí sucede, en cambio, en El nadador, cuya historia, según hemos dicho, se cuida de abrir la posibilidad de que los personajes salgan del acuario. Pienso que es la perspectiva crítica que se hace presente de manera progresiva en el relato de Zambra, en la que observador y observado intercambian sus papeles, la que desarticula el funcionamiento de la narración como dispositivo

\footnotetext{
${ }^{13}$ Los nombres de Cosmo y Wanda están tomados de la serie de televisión infantil Los padrinos mágicos. 
de vigilancia y que la hace culminar en una forma opuesta a la que tentativamente es posible considerar como una narrativa de la intemperie.

En efecto, la analogía departamento-acuario y el encierro que ella connota es calificada negativamente en la siguiente descripción en tercera persona, pero con focalización interna, por parte de Julián: "Está echado en el suelo, como un león en la jaula como un gato, más bien, o como esos peces excéntricos y horribles que la niña escogió" (76). Podemos leer la autorrepresentación de Julián, una autonomía sojuzgada que aporta la mención al rey de la selva enjaulado; luego, su degradación en el gato, como un animal doméstico pero que mantiene una cierta independencia; hasta llegar finalmente a los peces "excéntricos y horribles". Pero lo más importante es que al verlos se observa a sí mismo, y en esa mirada se revela lo familiar reprimido - lo ominoso o siniestro de Freud $-{ }^{14}$ de esa vida que es como la del león en una jaula o la de una planta en un invernadero, ${ }^{15}$ con un sustrato escondido, que es lo que permite visibilizar la narración del acuario. Así, más adelante el departamento de Julián se asemeja a la torre de espejos de Max Borda: "Soy el hijo de una familia sin muertos, dice, mirando la pared como si fuera una vidriera: Hola, soy el hijo de una familia sin muertos" (67, la cursiva es mía). Gracias a la intercambiabilidad del acuario, Julián como morador de un habitáculo transparente, se ve a sí mismo y se define y repite su extrañeza - 0 su "siniestro"- en estos términos: "el hijo de una familia sin muertos". Me parece que lo que hay aquí es una escritura palimpséstica que deja entrever lo olvidado y lo encubierto, según la cual la historia del acuario va dejando traslucir la del niño Julián en el año 1984, cuyo trasfondo inexpresado es la dictadura, los muertos y la ciudad. ${ }^{16}$ Los peces de los que nos habla Zambra son

\footnotetext{
${ }^{14}$ Es lo íntimo-hogareño que ha sido reprimido y ha retornado, según lo describe en Lo siniestro (Lo ominoso en la edición de Amorrortu).

${ }^{15}$ El bonsái que da título a la primera novela de Zambra, visto desde esta segunda obra, es también una figuración del encierro: "La imagen primera es la de un hombre joven dedicado a cuidar un bonsái. Si alguien le pidiera resumir su libro, probablemente respondería que se trata de 'un hombre joven que se dedica a cuidar un bonsái... un hombre encerrado con su bonsái, cuidándolo, conmovido por la posibilidad de una obra de arte verdadera'" (28-29, la cursiva es mía).

${ }_{16}$ Así, reflexiona el narrador focalizado en Julián y luego el propio personaje: "En lugar de encender una imagen muerta debió describir vidas como las de ese niño de 1984. En vez de hacer literatura debería haberse hundido en los espejos familiares. Pienso en una novela con solo dos capítulos: el primero, muy breve, consigna lo que ese niño por entonces sabía; el segundo, muy largo, virtualmente infinito, relata lo que en aquel tiempo ese niño no sabía" (71). Esta sería la novela que habría que escribir, según el narrador, y no la del bonsái: "Definitivamente ha perdido el tiempo con su idea fija de los bonsáis. Ahora piensa que el único libro que sería valioso escribir es un relato largo sobre aquellos días de 1984. Ese sería el único libro lícito, necesario" (68). Esto es lo que Zambra ha hecho, en cierto sentido, en Formas de volver a casa, su tercera obra narrativa, publicada en 2011, con la que cierra una suerte de tríptico. De esta forma, La vida privada de los árboles funciona como una especie de bisagra de la trilogía, que observa críticamente el primer volumen y adelanta el tercero.
} 
personajes enclaustrados en la vida familiar que estuvieron al margen de la violencia política de los setenta y ochenta y que siguen estándolo en sus espacios cerrados. Se trata, como lo indica uno de los epígrafes, de "árboles o náufragos”; y sus historias — según lo plantea el otro-, están detenidas, no transcurren.

La misma figuración de carencia y falta de agencia se repite en las fábulas que Julián le cuenta a Daniela. La primera trata de dos árboles inmovilizados en un parque que, a pesar de haber sido marcados por "vándalos", no pueden salir de su espacio para defenderse. La segunda, la historia de una pintora que ha debido dejar su vocación artística para consagrarse a recoger hojas en el parque, a causa del crecimiento extraordinario de sus brazos, es una alegoría de la situación de Verónica que ha tenido que abandonar la pintura a causa del embarazo y que, en cambio, se ha dedicado a preparar pasteles. Estas historias de imposibilidad y extrañeza, de renuncia y de quietud insostenibles explican la desaparición de Verónica y su no regreso; la destrucción de la familia nuclear o la imposibilidad del acuario; el retorno de la ciudad y de la lluvia "que va a limpiar el aire de Santiago" (114); el ejercicio del cambio - "Julián decidió que el futuro debía comenzar" (113) —; y el que la última frase del libro nos informe que el protagonista "deja ir" (117) a Daniela.

\section{MONSIEUR PAIN: EL ACUARIO COMO DOCUMENTO DE BARBARIE}

El tercer ejemplo, tomado de Monsieur Pain (1999) de Roberto Bolaño, es un relato que trata de una pesquisa realizada por el protagonista y vinculada a la muerte de César Vallejo, el acuario se vuelve proliferante, se deconstruye y se desarma, en el imaginario opuesto al de la intimidad, el de la intemperie, propio de este autor. ${ }^{17}$ La figura aparece acotada, en una escena de tres o cuatro páginas dispuestas casi en el centro de la nouvelle, en las que se narra la breve estadía de Pierre Pain en un café todo pintado de verde llamado El Bosque. Allí, los únicos clientes, son dos jóvenes hermanos, quienes le indican que mire una "enorme pecera rectangular" (70) que han creado, llamada el bosque submarino:

En el fondo de la pecera, sobre una arena muy fina, reposaban miniaturas de barcos, trenes y aviones, ordenados de tal forma que simulaban catástrofes, infortunios detenidos en un mismo tiempo artificial, por encima de los cuales circulaban indiferentes algunos peces rojos.

Las miniaturas, conjeturé, eran de plomo y su fidelidad detallística notable.

\footnotetext{
${ }^{17}$ Una explicación de la consideración de la obra de Bolaño como narrativa de la intemperie se encuentra en mi artículo citado en la bibliografía.
} 
- No hay cadáveres — murmuré, más para mí mismo que como una observación; el muchacho, no obstante, me oyó o tal vez adivinó mis palabras.

-Mire con cuidado —indicó.

En efecto, junto a uno de los trenes, a un lado del furgón de cola, yacía, semienterrada en la arenilla, una figurita con forma de hombre. Y no era la única: a poca distancia de un monoplaza, apoyada contra una piedra pómez, contemplaba el almanaque de calamidades otra figura, de metal sin pintar, gris oscura, y erguida, aunque uno adivinaba que si se retiraba la piedra la figura se derrumbaría sin remedio (70-71).

Las diferencias con las representaciones de las novelas de Contreras y Zambra son notables. Por una parte, la descripción es a contrapelo del procedimiento y de la inmovilidad propia del acuario, dialógica y temporalizada, en el sentido de que es constantemente interrumpida por la conversación de Pain con los hermanos y de que en ella se da cuenta del proceso de conocimiento que este tiene del acuario, paulatino y progresivo, hasta llegar a un "mirar bien". Por otra parte, se destacan varios rasgos distintivos: en contraste con el acuario de Zambra, que se encuentra en el departamento familiar, éste se halla en un lugar público, un café, donde está abierto a la observación; tampoco es un adorno elegido por una niña sino que un artificio producido, una suerte de obra de arte bizarra, algo "representado" por los hermanos. Además, los peces son aquí secundarios pues lo que importa ahora es el decorado, apenas presente en Contreras e inexistente en Zambra. Este está formado por miniaturas de los tres medios de transporte clave del "progreso" moderno: barcos, trenes y aviones, pero representando catástrofes, y por pequeñas figuras humanas destrozadas o hundidas, solo dos en el comienzo, sin número, después: "por unos instantes no supe discernir qué podían ser unos puntitos negros que sobresalían del fondo de la pecera, esparcidos a lo largo del tren. Luego me di cuenta: se trataba de cabezas seccionadas o bien de figuras enterradas hasta el cuello. Un reguero de cadáveres..." (71).

Los creadores - ausentes en los otros dos relatos- son una suerte de artistas que dan cuenta de su obra y que se dedican a su arte más allá de la incomprensión del público, sin hacer concesiones:

-Y la gente apenas se interesa por las miniaturas en pecera. De vez en cuando podemos vender alguna, sobre todo en Navidad, pero el que paga exige y nosotros sólo hacemos cementerios marinos. No estamos dispuestos a transigir. Si le contara los malentendidos.... Y lo avariciosa e ignorante que es la gente.... - Nos piden belenes, es divertido, ¿No le parece? Nos piden escenas de batallas, reproducciones históricas, a nosotros... (73, la cursiva es del texto). 
En tanto, lo que persiguen es el recuerdo reprimido, si consideramos la enigmática palabra que pronuncia uno de los hermanos: "-Pobres — dijo Alphonse. Y luego murmuró una frase ininteligible de la que sólo entendí la palabra anamnesis" (73, la cursiva es del texto).

Los clientes piden pesebres, batallas, reproducciones de la historia, mientras los hermanos representan catástrofes, infortunios, "almanaque de calamidades", cadáveres, cabezas cortadas; en síntesis, un reguero de dolor en "[u]n mundo... donde sólo ondeaban las banderas de la muerte: los peces rojos" (71). Me parece que en esta contraposición esencial Bolaño quiere mostrar el sustrato abisal en que se sostiene el imaginario de la intimidad, la protección del acuario y la vida privada de los peces, la historia palimpséstica que no deja emerger la novela de Contreras y que impide la continuación de la familia nuclear en Zambra.

A pesar de lo repetido de la cita, no se puede evitar, debido a su pertinencia, evocar la "Tesis IX" de Walter Benjamin (2008) sobre el ángel de la historia, que Bolaño, quizás sin quererlo, pareciera intentar ilustrarnos con su representación del acuario:

"En lo que para nosotros aparece como una cadena de acontecimientos, él ve una catástrofe única, que arroja a sus pies ruina sobre ruina, amontonándolas sin cesar. El ángel quisiera detenerse, despertar a los muertos y recomponer lo destruido. Pero un huracán sopla desde el paraíso... Este huracán es lo que nosotros llamamos progreso" (45).

Así, con la deconstrucción del imaginario del acuario propio de la novela de la intimidad y su representación a contrapelo, Bolaño efectúa una anamnesis que pone en el primer plano de la visión lo olvidado, los muertos que no hubo en la familia de Julián pero sí en las de otros, aquello que, valiéndome de nuevo de Benjamin, podría ser lo dicho en otra de sus tesis, la VII: "No hay documento de cultura que no sea a la vez un documento de barbarie" (110).

En síntesis, en El nadador aparece una representación básica del espacio de la intimidad a través del acuario y de sus personajes como peces, es decir, como sujetos psicológicos sometidos a la observación externa y a la autoobservación, que están encerrados en sus relaciones amorosas, consideradas la única instancia real. Como novela de la intimidad funciona también al modo de un dispositivo de vigilancia que sostiene la permanencia de esta configuración, la que se consolida en el final feliz. En La vida privada de los árboles, la mirada del narrador sobre sí mismo hace posible una visión crítica de este imaginario, al dejar traslucir su trasfondo de violencia histórica, que lo contagia de una extrañeza imbuida de siniestro, lo cual conlleva a la imposibilidad de su mantención. Podríamos decir que aquí falla la narración de la intimidad como andamiaje que sostiene el espacio de lo privado y se avizora 
una narrativa de lo abierto. En Monsieur Pain se deconstruye la imagen al ubicar en el primer plano el sustrato de barbarie, la catástrofe fundamental que subyace a las representaciones del acuario. Se figura aquí, a contrapelo de la intimidad, el imaginario de la intemperie.

Se trata entonces de subjetividades que intentan curarse del miedo y asegurarse una protección en la intimidad contra la intemperie del capitalismo tardío en volúmenes de vidrio incapaces de otorgarla, pues su transparencia exige la mirada, la vigilancia y el control, como se muestra en la novela de Contreras. Esta figuración aparece como un fragmento significativo del imaginario de la narrativa chilena de la posdictadura, representación que la obra de Zambra que se analizó muestra en su imposibilidad y que la novela de Bolaño destruye.

\author{
Pontificia Universidad Católica de Chile* \\ Facultad de Letras \\ Departamento de Literatura \\ Avda. Vicuña Mackenna 4860 Macul, Santiago (CHILE) \\ mareco@uc.cl
}

\title{
OBRAS CITADAS
}

Areco, Macarena. "Bolaño no íntimo o la novela de la intemperie", en Roberto Bolaño. La experiencia del abismo, Fernando Moreno (coord.). Santiago: Lastarria, (2011):53-60.

Baradit, Jorge. Ygdrasil. Buenos Aires: Ediciones B, 2005.

Barthes, Roland. Mitologías. 1957. Trad. Héctor Schmucler. México: Siglo XXI, 1997.

------ S/Z. México, Siglo XXI, 1991.

Benjamin, Walter. Tesis sobre la historia y otros fragmentos. Edición, traducción e introducción de Bolívar Echeverría. México D.F.: UACM e Itaca, 2008.

Bolaño, Roberto. Monsieur Pain. Barcelona: Anagrama, 1999.

Cánovas, Rodrigo. "De los espacios que restan en la narrativa chilena actual", Literatura y lingüística 11 (1998). Disponible en:

http://www.scielo.cl/scielo.php?script=sci_arttext\&pid=S0716-

58111998001100010.

Castoriadis, Cornelius. La institución imaginaria de la sociedad. Buenos Aires: Tusquets, 2007.

Contreras, Gonzalo. El nadador. Santiago: Alfaguara, 1995. 
Culler, Jonathan. "La literatura y los estudios culturales". En Breve introducción a la teoría literaria. 57-70, Barcelona: Crítica, 2000.

Eco, Umberto. "La línea y el laberinto." Disponible en: http://www.temakel.com/texolvueco.htm

Freud, Sigmund. Lo siniestro (1919). Obras completas VII. Trad. Luis López Ballesteros. Madrid: Biblioteca Nueva, 1974.

García Canclini, Néstor. La globalización imaginada. Buenos Aires: Paidós, 1999.

Guerrero, Eduardo. "Encuentro con escritores chilenos", Finisterrae 8 (2000): 99-103. Disponible en:

http://www.memoriachilena.cl/archivos2/pdfs/MC0036121.pdf

Jameson, Frederic. El posmodernismo o la lógica cultural del capitalismo avanzado. Trad. José Luis Pardo. Barcelona, Paidós, 1991.

Lakoff, George y Mark Johnson. Metáforas de la vida cotidiana. Madrid: Cátedra, 2001.

Laplanche, Jean y Pontalis, Jean-Bertrand. Diccionario de psicoanálisis. Barcelona: Labor, 1994.

Ludmer, Josefina. Aqui América Latina: una especulación. Buenos Aires: Eterna cadencia, 2010.

Zambra, Alejandro. Bonsái. Barcelona: Anagrama, 2006. La vida privada de los árboles. Barcelona: Anagrama, 2007. 